Engineering

Electrical Engineering fields

\title{
Control and performance of a pulse-density-modulated series-resonant inverter for corona discharge processes
}

Hideaki Fujita

Okayama University
Hirofumi Akagi

Okayama University

This paper is posted at eScholarship@OUDIR : Okayama University Digital Information Repository.

http://escholarship.lib.okayama-u.ac.jp/electrical_engineering/23 


\title{
Control and Performance of a Pulse-Density-Modulated Series-Resonant Inverter for Corona Discharge Processes
}

\author{
Hideaki Fujita, Member, IEEE, and Hirofumi Akagi, Fellow, IEEE
}

\begin{abstract}
This paper presents control and performance of a pulse-density-modulated (PDM) series-resonant voltage-source inverter developed for corona discharge processes. The PDM inverter produces either a square-wave ac-voltage state or a zerovoltage state at its ac terminals to control the average output voltage under constant dc voltage and operating frequency. This results in a wide range of power control from $0.5 \%$ to $100 \%$, even in the corona discharge load with a strong nonlinear characteristic. A 30-kHz 6-kW surface treatment system consisting of a voltage-source PDM inverter, a step-up transformer, and a corona discharge treater shows the establishment of a stable corona discharge in an extremely wide range of power control and, therefore, succeeds in performing both strong and weak surface treatment processes for film.
\end{abstract}

Index Terms - Corona discharge, power control, pulse-density modulation, series-resonant inverter.

\section{INTRODUCTION}

$\mathbf{I}$ $\mathrm{N}$ RECENT YEARS, significant progress has been made in switching speed and voltage/current rating of semiconductor power devices, such as insulated gate bipolar transistors (IGBT's) and power MOSFET's. This has made a great contribution to the proliferation of pulsewidth modulation (PWM) inverters for adjustable-speed drives and high-frequency highpower resonant inverters for induction heating applications, such as melting, surface quenching, and tube welding [1]-[4].

The purpose of corona discharge treatment is to render the affinity of polyethylene film to ink, glue, and coating [5], [6]. In general, corona discharge processes require specially designed ac power supplies of $10-20 \mathrm{kV}, 20-50 \mathrm{kHz}$, and $1-40 \mathrm{~kW}$ to maintain a stable corona discharge in air at atmospheric pressure. Moreover, the capability of adjusting the affinity and adaptability to various kinds of film differing in thickness and/or material requires an ac power supply capable of controlling the discharge power in a wide range of $1 \%-100 \%$.

Paper IPCSD 98-87, presented at the 1998 Industry Applications Society Annual Meeting, St. Louis, MO, October 12-16, and approved for publication in the IEEE TRANSACTIONS ON INDUSTRY APPLICATIONS by the Industrial Power Converter Committee of the IEEE Industry Applications Society. Manuscript released for publication December 29, 1998.

The authors are with the Department of Electrical Engineering, Okayama University, Okayama 700-8530, Japan.

Publisher Item Identifier S 0093-9994(99)03843-8.
An ac power supply for a corona discharge processes comprises a diode or thyristor bridge rectifier, a voltagesource series-resonant inverter, and a step-up transformer with a secondary voltage rating of over $20 \mathrm{kV}$. The ac power supply basically has the same power circuit topology as that for induction heating, except for the use of either a step-up transformer or a step-down transformer. However, the corona discharge treater exhibits a strong nonlinear characteristic of voltage and current. Due to this nonlinearity, a conventional voltage-source series-resonant inverter based on either dc-bus voltage control or frequency control [7], [8] has difficulty in controlling the discharge power in a wide range of $1 \%-100 \%$.

This paper introduces pulse-density modulation (PDM) to a $30-\mathrm{kHz} 6-\mathrm{kW}$ voltage-source series-resonant inverter for corona discharge treatment. A broad range of power control is obtained by the PDM inverter which controls the duration of a zero-voltage state at its output terminals in synchronization with the resonant frequency of the series-resonant circuit. Although the PDM in this paper is somewhat similar in operating principle to the "discontinuous mode control" in [9], a significant difference in output voltage and current waveforms exists between the two [10]. A sophisticated control circuit based on a phase-locked loop (PLL) makes the PDM inverter achieve zero-voltage switching (ZVS) and quasi-zerocurrent switching (ZCS) in all the load conditions. This paper pays much attention to the control circuit which follows that presented in [10]. The oscillating frequency of the PLL circuit always follows the resonant frequency; nevertheless, the actual average switching frequency of the IGBT's varies in a range of $600 \mathrm{~Hz}-30 \mathrm{kHz}$. An experimental system of $30 \mathrm{kHz}$ and $6 \mathrm{~kW}$ verifies the establishment of a stable corona discharge in an extremely wide range of power control from $0.5 \%-100 \%$.

\section{CORONA Discharge System}

\section{A. System Configuration}

Fig. 1 shows the power circuit configuration of a corona discharge treatment system developed in this paper. The 30$\mathrm{kHz} 6-\mathrm{kW}$ inverter consists of a single-phase voltage-source H-bridge inverter using two IGBT modules. Each two-in-one IGBT module is rated at $600 \mathrm{~V}$ and $50 \mathrm{~A}$. A lossless snubbing 


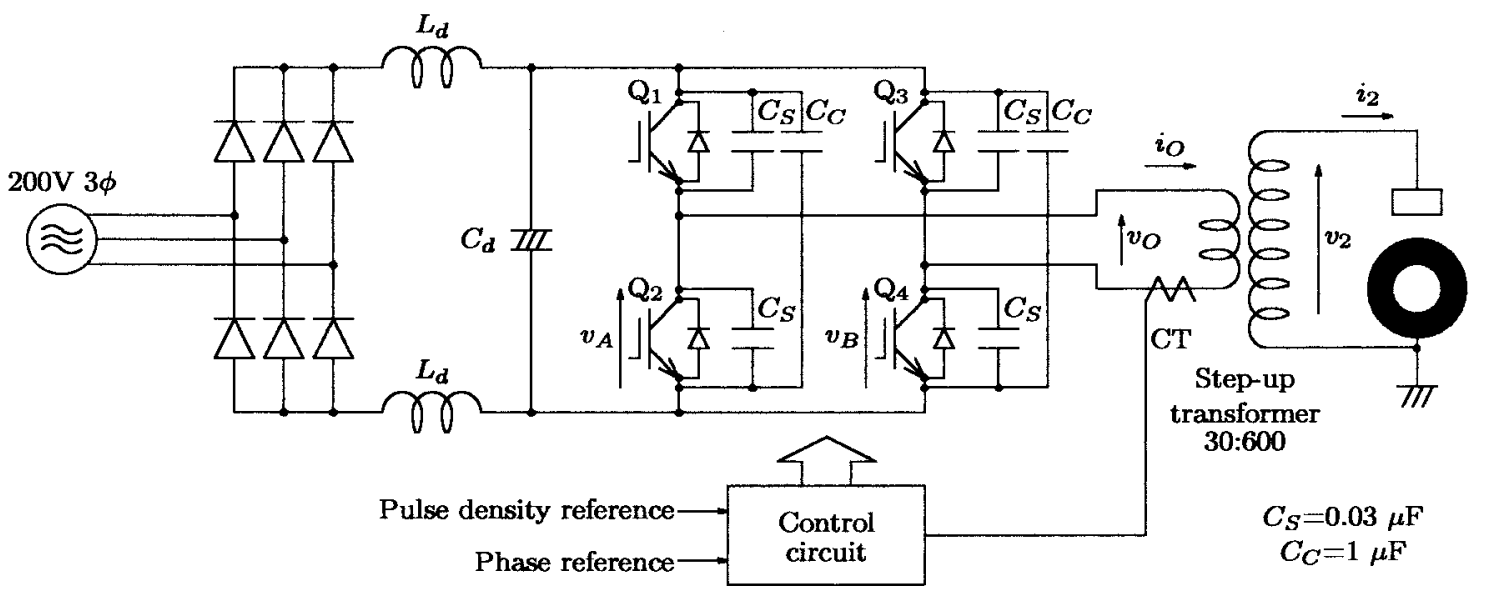

Fig. 1. Corona discharge treatment system.

capacitor $C_{S}=0.03 \mu \mathrm{F}$ is connected between the collector and emitter of each IGBT, and a high-frequency dc capacitor $C_{C}=1 \mu \mathrm{F}$ is connected between the dc terminals of each IGBT module. The lossless snubbing capacitor enables the voltage-source inverter to perform ZVS when the inverter operates with a lagging load current. This means that the inverter operating frequency should be higher than the load resonant frequency. In addition, quasi-ZCS is also achieved because a PDM inverter operates at a constant frequency in any power control conditions. Thus, ZVS and quasi-ZCS result in a significant reduction of switching losses. A detailed description of ZVS and quasi-ZCS operation in the PDM inverter was made in [4].

A step-up transformer with ferrite core, the turn ratio of which is 1:20, is installed on the ac terminals of the inverter in order to obtain a high voltage of $10-20 \mathrm{kV}$ for corona discharge treatment. An equivalent load of the inverter can be considered an $L C R$ series-resonant circuit comprising a leakage inductor of the transformer and a nonlinear lossy capacitor existing between the electrodes of the corona discharge treater.

\section{B. Structure of Electrodes}

Fig. 2 shows the structure of electrodes in a corona discharge treater for film web. Film passes through an air gap of around $3 \mathrm{~mm}$ between a bar electrode and a grounded roll electrode. The grounded roll electrode is coated with a buffer dielectric to avoid a sudden transition from corona discharge to arc discharge. When an ac voltage of $20-50 \mathrm{kHz}$ and $10-20$ $\mathrm{kV}$ is applied to the bar electrode, breakdown occurs in the air gap. During breakdown, corona discharge provides the film passing through the air gap with the affinity to ink.

The capability of adjusting the affinity and adaptability to various kinds of film differing in thickness and/or material requires an ac power supply capable of controlling the discharge power in a wide range of 1\%-100\%. Generally, discharging loads have a strong nonlinear relationship between their voltage and current. A large amount of current is drawn into the corona discharge treater when the electrodes voltage is higher than the breakdown voltage. When the electrodes

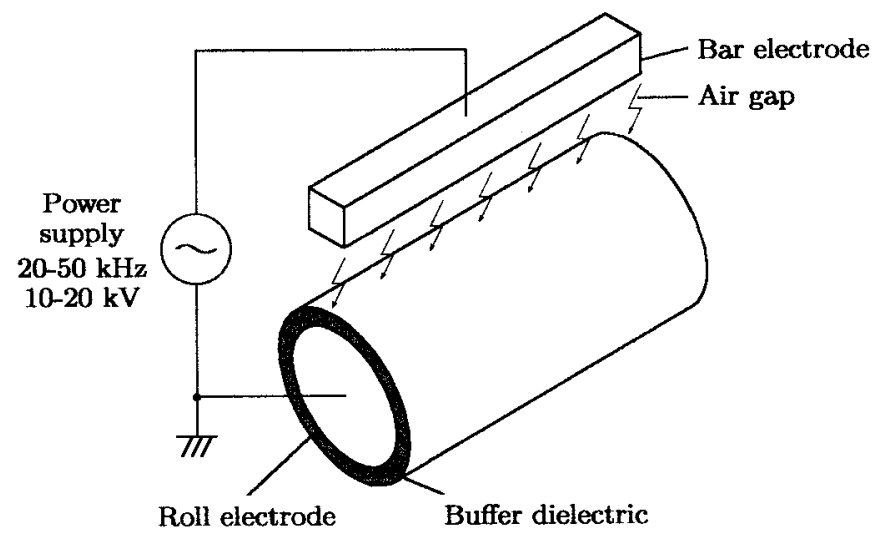

Fig. 2. Structure of electrodes.

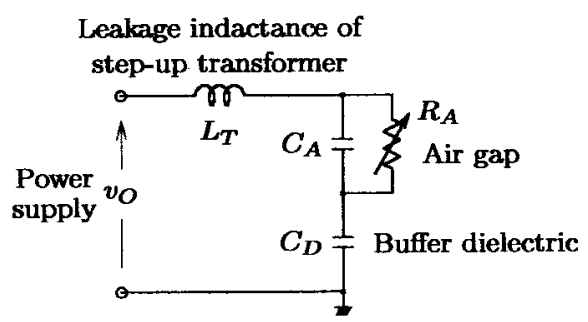

Fig. 3. Equivalent circuit of transformer and electrodes.

voltage is lower than the breakdown voltage, almost no current flows and no discharge occurs.

\section{Nonlinear Characteristics in Corona Discharge}

Fig. 3 shows an equivalent circuit of the transformer and the electrodes. An equivalent capacitor $C_{A}$ and variable resistor $R_{A}$ represent an impedance of the air gap, $L_{T}$ is a leakage inductance of the step-up transformer, and $C_{D}$ is the capacitance of the buffer dielectric. Corona discharge exhibits a strong nonlinear characteristic in voltage and current because the equivalent resistor $R_{A}$ varies with the voltage applied to the electrodes. The resistor $R_{A}$ is almost infinity while the 


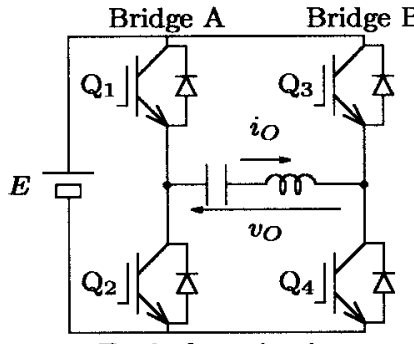

Equivalent circuit.

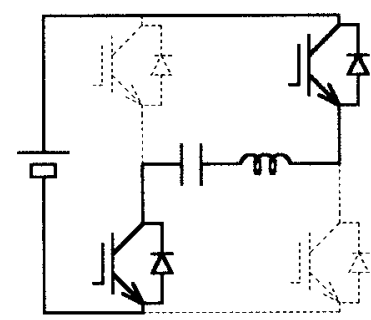

(b) Mode II.

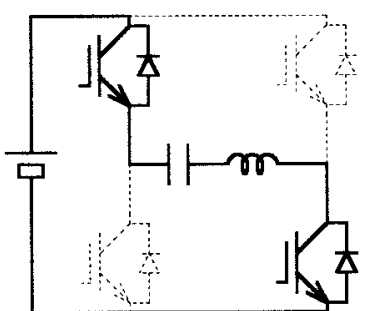

(a) Mode I.

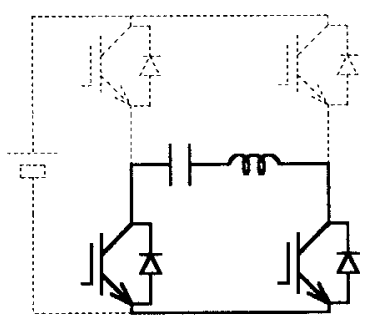

(c) Mode III.
Fig. 4. Switching modes in PDM inverter.

applied voltage is less than the breakdown voltage, and then no discharge occurs. When the electrode voltage is more than the breakdown voltage, the resistor $R_{A}$ decreases and shorts out the capacitance $C_{A}$. Thus, a large amount of discharge current flows, and the resonant frequency slightly decreases.

So far, dc-voltage control and frequency control have been practically applied to voltage-source series-resonant inverters for the purpose of adjusting their output power. It is, however, difficult for the conventional controls to adjust the discharge power to less than half of the full power, because the electrodes voltage would be lower than the breakdown voltage. Moreover, a low-power operation may be accompanied by a partial or local corona discharge due to inequality of the gap between the bar and roll electrodes.

\section{PRINCIPLE OF PDM}

Fig. 4 shows the switching modes of the voltage-source series-resonant PDM inverter. For the sake of simplicity, the combination of the step-up transformer and the corona discharge treater is represented by an $L C R$ series-resonant circuit. A conventional voltage-source series-resonant inverter takes alternate mode I and mode II in Fig. 4(a) and (b) to produce a square-wave ac-voltage state. In addition to modes I and II, the PDM inverter introduces mode III to produce a zero-voltage state at its output terminals. During mode III, a gate turn-on signal is provided to both lower leg IGBT's, $Q_{2}$ and $Q_{4}$, in half-bridge inverters $A$ and $B$. As a result, both one IGBT and a diode connected in antiparallel to the other IGBT remain turned on, thus forming a bidirectional free-wheeling circuit for the output current $i_{O}$, as shown in Fig. 4(c).

Fig. 5 illustrates the principle of the PDM-based power control. The PDM inverter frequently repeats "run and stop" in accordance with a control sequence to adjust its average output voltage, synchronized with the resonant current of the series-resonant load. Fig. 5 corresponds to the case of a pulse

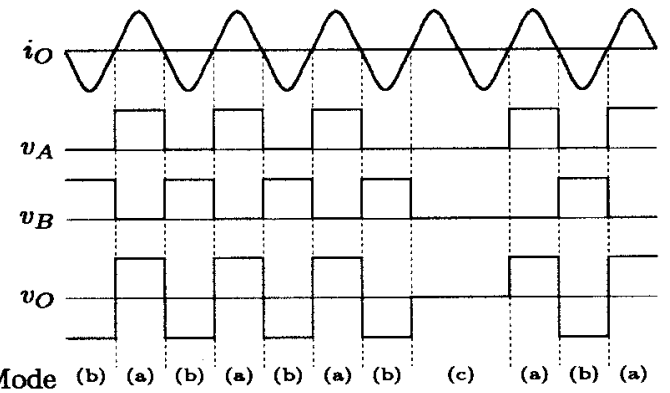

Fig. 5. Principle of PDM control.

density of 3/4. Taking alternate mode I and mode II every half resonant cycle, the PDM inverter creates the square-wave ac voltage with the amplitude of $E$ for three resonant cycles. The PDM inverter, however, takes mode III during the subsequent one cycle and, therefore, produces the zero-voltage state. When attention is paid to the four resonant cycles, the output voltage of the PDM inverter is a periodic waveform. Hence, the average output voltage is $3 / 4$ of the maximum output voltage with unity pulse density. Note that no dc component is included in the waveform of the output voltage $v_{O}$; otherwise flux saturation would occur in the step-up transformer with ferrite core.

\section{CONTROL Circuit}

Fig. 6 shows a block diagram of the control circuit developed for the PDM inverter. The control circuit is divided into the following two parts:

- PLL circuit for PDM control;

- PDM circuit for duration control of the zero-voltage state.

\section{A. PLL Circuit for PDM Control}

The PLL circuit consists of a phase detector (PD), a lowpass filter (LPF1) and a voltage-controlled oscillator (VCO), along with an analog switch (AS) and a peak current detector (PCD). Because it is impossible to precisely detect a very small amount of current, a conventional PLL circuit does not work properly during weak surface treatment which needs to lower the discharge power into $1 \%-10 \%$ of the full power. The combination of the AS and the PCD plays an important role in solving the problem. The output signal from the PCD opens and closes the AS, which is installed on the input side of the LPF1. While the peak value of the output current is larger than a preset level, the AS remains closed, thus resulting in a conventional PLL circuit. On the other hand, when the peak value is smaller than the preset level, the AS is opened. In this case, a $0.068-\mu \mathrm{F}$ capacitor in the LPF1 enables the $\mathrm{VCO}$ to continue oscillating at the same frequency as the operating frequency of the VCO just before opening the AS. The $0.068-\mu \mathrm{F}$ capacitor, along with the opened analog switch, acts like a memory device storing the resonant frequency of the series-resonant load.

\section{B. PDM Control Circuit}

The part enclosed with a broken line in Fig. 6 corresponds to the PDM control circuit based on feedback control, and the 


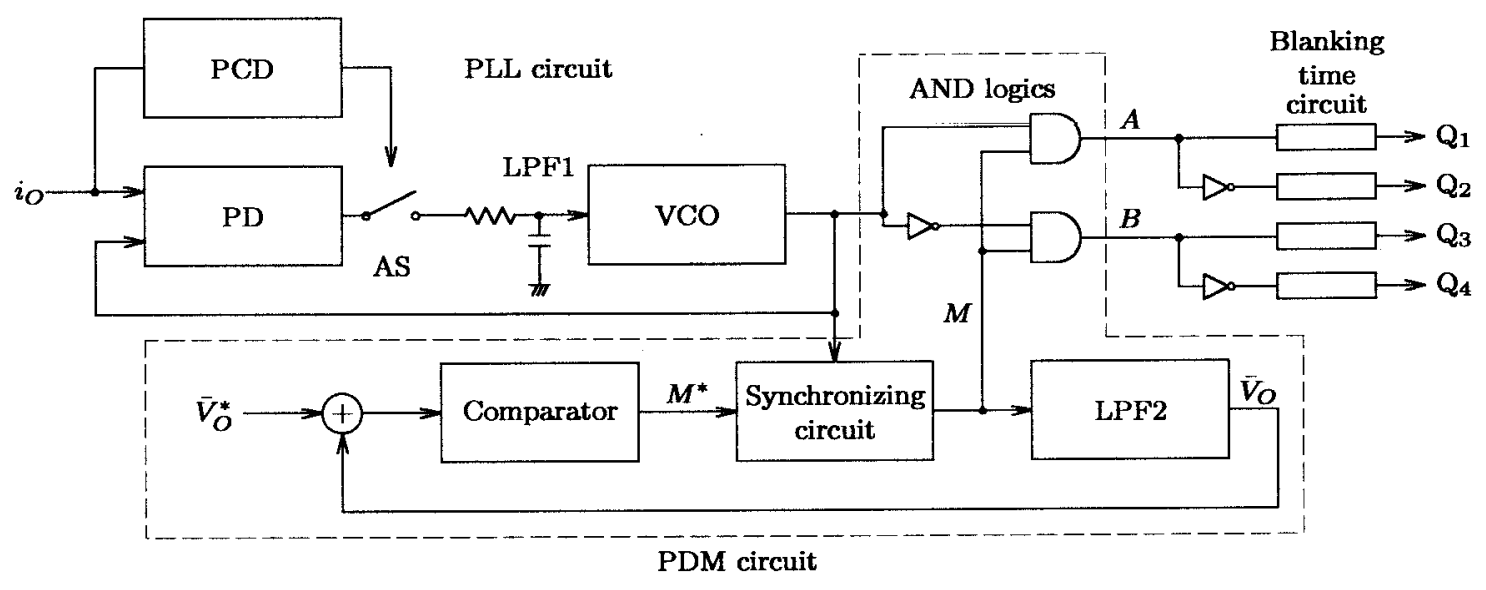

Fig. 6. Block diagram of control circuit.

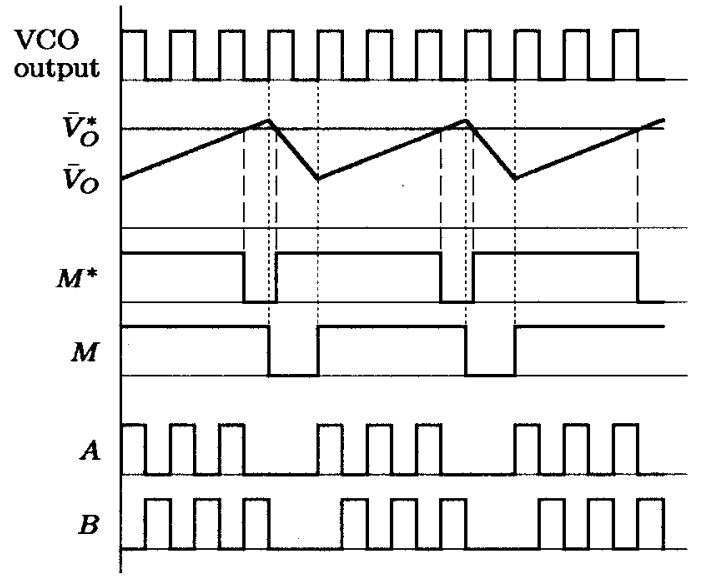

Fig. 7. Signal waveforms in the control circuit.

control signal waveforms are shown in Fig. 7. The average output voltage reference $\bar{V}_{O}^{*}$ adjusts the duration of the zerovoltage state. The actual average output voltage $\bar{V}_{O}$ is obtained from a logic signal corresponding to the actual ac-voltage state $M$ via a low-pass filter (LPF2). The corona discharge treatment system developed in this paper is intended to operate in a wide range of pulse density from $1 / 50$ to 1 . The inverter output voltage $v_{O}$ has various low-frequency components caused by the PDM control. The most dominant frequency is $600 \mathrm{~Hz}$ $(=30 \mathrm{kHz} / 50)$ under the conditions of a resonant frequency of $30 \mathrm{kHz}$ and a pulse density of $1 / 50$. Therefore, the cutoff frequency of the LPF2 is designed to be $160 \mathrm{~Hz}$. Comparison of $\bar{V}_{O}^{*}$ with $\bar{V}_{O}$ by means of an analog comparator generates a logic signal of the ac-voltage state reference $M^{*}$, choosing which state the PDM inverter produces, either the square-wave ac-voltage state or the zero-voltage state for the subsequent resonant cycle.

A synchronizing circuit consisting of a D-type flip-flop device is employed to avoid the change of the current state during the resonant cycle even when the ac-voltage state reference $M^{*}$ changes. The VCO output and the ac-voltage state reference $M^{*}$ are applied to the synchronizing circuit as clock and data signals, respectively. The synchronizing circuit takes in $M^{*}$ at every rising edge of the VCO output and holds the logic signal $M$ during the subsequent resonant cycle, as shown in Fig. 7. A logic "AND" circuit produces alternate mode I and mode II during the square-wave ac-voltage state of $M=1$, whereas it produces mode III during the zero-voltage state of $M=0$. Note that signal $B$ is not equal to an inversion of $A$ due to existence of mode III during the zero-voltage state. Signals $A$ and $B$ and their inverted signals are provided to four blanking time circuits which produce a time interval as short as $2 \mu$ s to avoid short circuiting of the dc-link input.

Note that mode II always follows mode I because the logic signal $M$ does not change for at least one resonant cycle. Hence, no dc component is included in the output voltage $v_{O}$. However, each gate signal includes a dc component and, therefore, a photocoupler taking the place of a pulse transformer achieves electric isolation of a gate signal in the control circuit from the corresponding gate drive circuit. Although the sophisticated PDM control circuit cannot continuously adjust the pulse density in theory, it is considered to have the capability of performing continuous power control in practice, because it forms continuous feedback control based on the detected average output voltage.

\section{EXPERIMENTAL RESULTS}

Figs. 8-10 show experimental waveforms of the inverter output current and voltage, $i_{O}$ and $v_{O}$, under the condition of a constant dc-bus voltage of $v_{d}=250 \mathrm{~V}$.

Fig. 8 corresponds to the case of maximum power operation at unity pulse density by producing no zero-voltage state. The dc input power of the inverter is $5.6 \mathrm{~kW}$. Fig. 9 shows experimental waveforms during operation at a pulse density of $1 / 2$. The PDM inverter creates alternating square-wave ac-voltage states and zero-voltage states and, therefore, the average output voltage is half as low as the maximum output voltage shown in Fig. 8. The dc input power is $1.9 \mathrm{~kW}$, which is only $33 \%$ of the maximum power of $5.6 \mathrm{~kW}$. The quality factor of the $L C R$ series-resonant circuit equivalent to the corona discharge treater including the step-up transformer is 


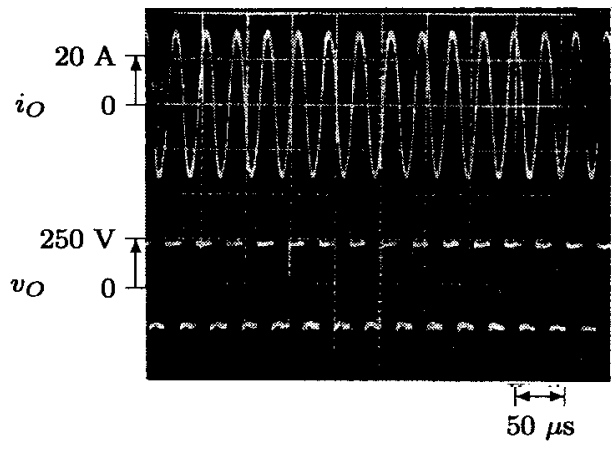

Fig. 8. Experimental waveforms in case of full-power operation.

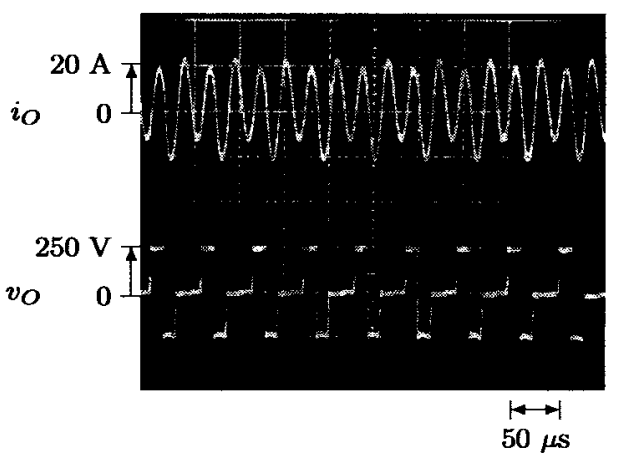

Fig. 9. Experimental waveforms in case of PDM control (pulse density 1/2).

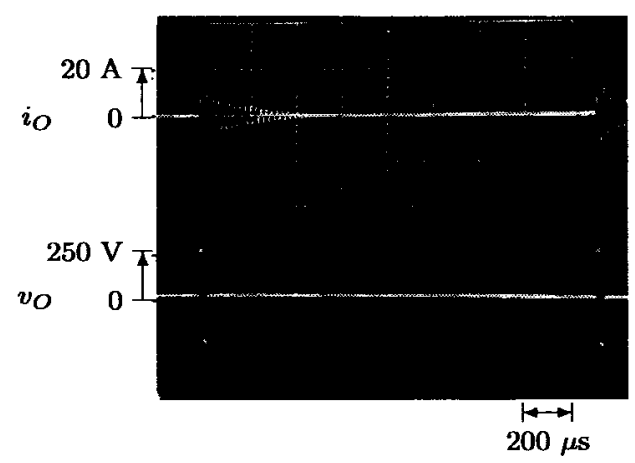

Fig. 10. Experimental waveforms in case of minimum output power by using PDM control (pulse density 1/50).

4.5, which is much smaller than the quality factor of $10-30$ in high-frequency induction heating systems. Therefore, the amplitude of the output current decays to $60 \%$ in the duration of the zero-voltage state, although $i_{O}$ is continuous.

Fig. 10 shows experimental waveforms in the case of minimum power operation at a pulse density of $1 / 50$. The PDM inverter produces the square-wave ac-voltage state once every 50 resonant cycles, and it continues to produce the zero-voltage state for the other 49 resonant cycles. The dc input power is 28 $\mathrm{W}$, which is only $0.5 \%$ of $5.6 \mathrm{~kW}$. Note that the inverter output current $i_{O}$ decays and reaches a value of zero in the duration of the zero-voltage state, resulting in significant difficulty to detect its phase or frequency. Opening the analog switch AS in Fig. 6 prevents the capacitor in the LPF1 from discharging

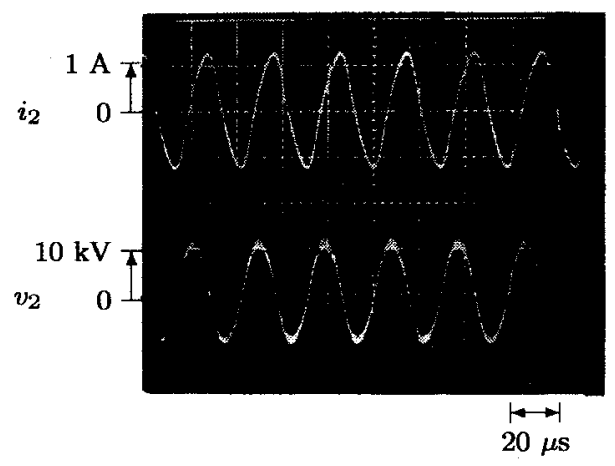

Fig. 11. Voltage and current waveforms of electrodes in case of dc voltage control.

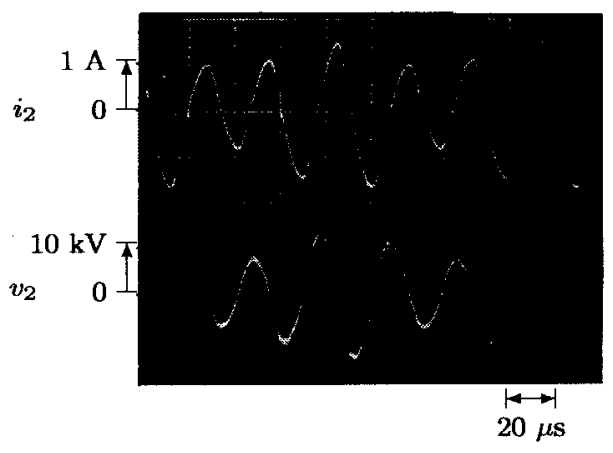

Fig. 12. Voltage and current waveforms of electrodes in case of PDM control.

and, thus, results in continuous oscillation of the $\mathrm{VCO}$ at the same frequency as the operating frequency of the VCO just before opening the AS. As a result, the output frequency of the inverter in the duration of the subsequent square-wave ac-voltage state coincides with the resonant frequency of the corona discharge load.

Figs. 11 and 12 show measured waveforms of the bar electrode voltage $v_{2}$ and the discharge current $i_{2}$ under the conditions of a dc-bus voltage of $200 \mathrm{~V}^{1}$ and a dc input power of $1.9 \mathrm{~kW}$. The bar electrode voltage and the discharge current are identical to the secondary voltage and current of the step-transformer, respectively. Fig. 11 shows the measured waveforms under the dc-bus voltage of $140 \mathrm{~V}$ at unity pulse density. The amplitudes of $v_{2}$ and $i_{2}$ are constant due to the dc-bus voltage control, and the maximum voltage of $v_{2}$ is 13 $\mathrm{kV}$. Fig. 12 corresponds to the case of the PDM control at a pulse density of $2 / 3$. Although the amplitudes of $v_{2}$ and $i_{2}$ fluctuate, the maximum voltage of $v_{2}$ is $16 \mathrm{kV}$.

Fig. 13 shows experimental relationships between the dc input power and the maximum voltage of $v_{2}$. As the dc input power is gradually lowered from $3.6 \mathrm{~kW}$, the electrode voltage sharply decreases in both the dc-bus voltage control and the frequency control cases, and then it drops to less than $10 \mathrm{kV}$ at $1 \mathrm{~kW}$, accompanied by a partial corona discharge in the air gap. On the other hand, the PDM control can keep the maximum

\footnotetext{
${ }^{1}$ Because of the use of a $20-\mathrm{kV}$ probe in this measurement, the dc-bus voltage is reduced from 250 to $200 \mathrm{~V}$ for safety.
} 


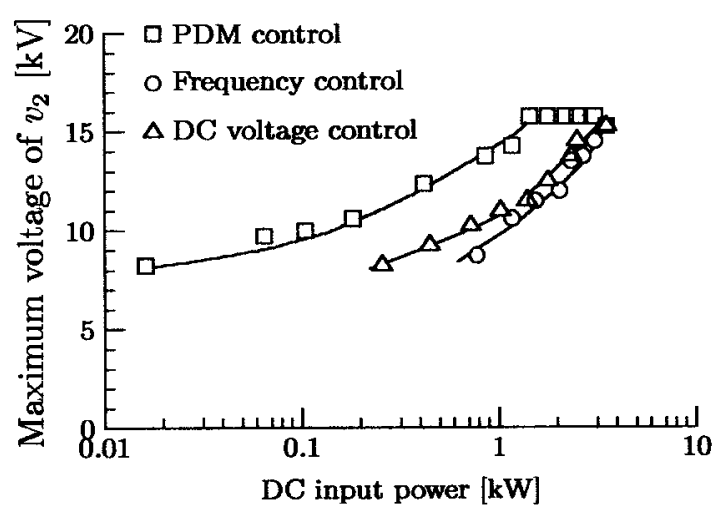

Fig. 13. Relationships between dc input power and maximum voltage of $v_{2}$.

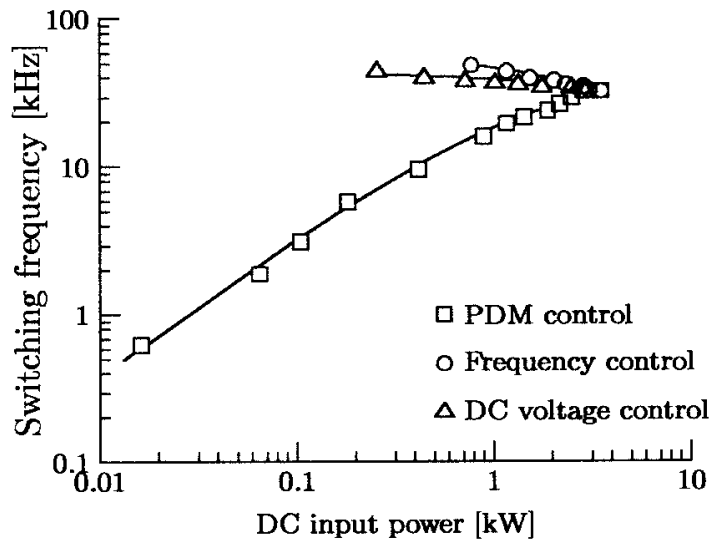

Fig. 14. Relationships between dc input power and average switching frequency $f_{\mathrm{SW}}$.

voltage of $v_{2}$ being $15 \mathrm{kV}$ when the dc input power is lowered from 3.6 to $1.5 \mathrm{~kW}$. As the dc input power is lowered from $1.5 \mathrm{~kW}$, the electrode voltage gradually decreases, and then it drops to less than $10 \mathrm{kV}$ at $0.1 \mathrm{~kW}$; nevertheless, a stable corona discharge is maintained equally throughout the air gap.

Fig. 14 shows experimental relationships between the dc input power and the average switching frequency $f_{\text {SW }}$. Note that the average switching frequency is defined by the actual switching times per second. The average switching frequency in the PDM control is lower than the resonant frequency except for operation at unity pulse density, whereas the average switching frequency in either the dc-bus voltage control or the frequency control is always equal to the resonant frequency. Because of the strong nonlinearity of corona discharge, the resonant frequency goes up as the dc input power goes down. The reason is as follows. During strong corona discharge treatment processes, the air gap between the electrodes is so gaseous as to be considered a short-circuit state. As a result of the shortcircuit state, the total capacitance between the electrodes is nearly equal to the capacitance existing in the buffer dielectric with which the grounded roll electrode is coated. In contrast, during weak corona discharge treatment processes, the total capacitance decreases because the capacitance equivalent to the air gap is connected in series to the buffer capacitance.
When the PDM inverter continuously produces the zerovoltage state, no switching occurs in any of the four IGBT's. The average switching frequency significantly goes down, thus contributing to a considerable reduction of the switching loss during low-power operation.

It is confirmed by experiment that stable corona discharge is obtained without any partial discharge, even under the minimum power condition as low as $28 \mathrm{~W}$ (1/50 pulse density). Although discontinuous discharge occurs in such condition, the PDM inverter does not produce any bad effect on surface treatment process for film. Usually, film passes through a corona discharge treater in a speed range from 1 to $2 \mathrm{~m} / \mathrm{s}$, and the width of the bar electrode is $20 \mathrm{~mm}$. Thus, six-times corona discharges are applied to the film during its passes between the electrodes, even under the pulse density of 1/50.

\section{CONCLUSION}

This paper has proposed a voltage-source series-resonant PDM inverter for corona discharge treatment. The PDM inverter has enabled control of the discharge power in a wide range of $0.5 \%-100 \%$, so as to perform both strong and weak surface treatment processes for film. In addition, the PDM inverter can achieve ZVS and quasi-ZCS in all operating conditions, thus leading to a significant reduction of switching loss and electromagnetic interference.

The experimental system consisting of a $30-\mathrm{kHz} 6-\mathrm{kW}$ voltage-source PDM inverter, a step-up transformer with a turn ratio of 1:20, and an actual corona discharge treater has verified the viability and effectiveness of the PDM inverter for corona discharge treatment processes.

\section{REFERENCES}

[1] W. E. Frank and C. F. Der, "Solid state RF generators for induction heating applications," in Conf. Rec. IEEE-IAS Annu. Meeting, 1982, pp. 939-944.

[2] S. Bottari, L. Malesani, and P. Tenti, "High frequency $200 \mathrm{kHz}$ inverter for induction heating applications," in Proc. IEEE PESC'85, 1985, pp. 308-316.

[3] L. Grajales, J. A. Sabate, K. R. Wang, W. A. Tabisz, and F. C. Lee, "Design of a $10 \mathrm{~kW} 500 \mathrm{kHz}$ phase-shift controlled series-resonant inverter for induction heating," in Conf. Rec. IEEE-IAS Annu. Meeting, 1993, pp. 843-847.

[4] H. Fujita and H. Akagi, "Pulse-density-modulated power control of a 4 kW $450 \mathrm{kHz}$ voltage-source inverter for induction melting applications," IEEE Trans. Ind. Applicat., vol. 32, pp. 279-286, Mar./Apr. 1996.

[5] L. A. Rosenthal and D. A. Davis, "Electric characterization of a corona discharge for surface treatment," in IEEE Trans. Ind. Applicat., vol. IA-11, pp. 328-335, May/June 1975.

[6] H. Akagi and A. Nabae, "A voltage-source inverter using IGBT's for a $50 \mathrm{kHz} 10 \mathrm{kV}$ corona surface treater," in Conf. Rec. IEEE-IAS Annu. Meeting, 1989, pp. 1164-1169.

[7] P. P. Roy, S. R. Doradla, and S. Deb, "Analysis of the series resonant converter using a frequency domain model," in Proc. IEEE PESC'91, 1991, pp. 482-489.

[8] A. Dmowski, R. Bugyi, and P. Szewczyk, "A novel series-resonant $\mathrm{dc} / \mathrm{dc}$ converter with full control of output voltage at no-load condition. Computer simulation based design aspects," in Conf. Rec. IEEE-IAS Annu. Meeting, 1992, pp. 924-928.

[9] J. G. Kassakian, M. F. Schlecht, and G. C. Verghese, Principles of Power Electronics. Reading, MA: Addison-Wesley, 1991, pp. 223-226.

[10] H. Fujita, S. Ogasawara, and H. Akagi, "An approach to a broad range of power control in voltage-source series-resonant inverter for corona discharge treatment-Pulse-density-modulation," in Proc. IEEE-PELS PESC'97, 1997, pp. 1000-1006. 


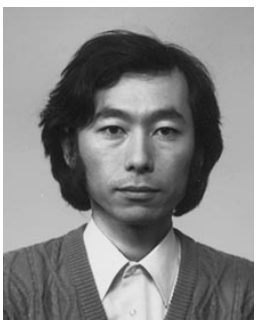

Hideaki Fujita (M'91) received the B.S. and M.S. degrees in electrical engineering from Nagaoka University of Technology, Nagaoka, Japan, in 1988 and 1990, respectively.

Since 1991, he has been a Research Associate in the Department of Electrical Engineering, Okayama University, Okayama, Japan. His research interests are static var compensators, active power filters, and resonant converters.

Mr. Fujita received First Prize Paper Awards from the Industrial Power Converter Committee of the IEEE Industry Applications Society in 1990, 1995, and 1998.

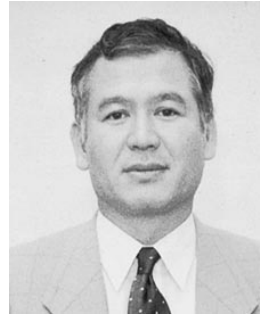

Hirofumi Akagi (M'87-SM'94-F'96) was born in Okayama-City, Japan, in 1951. He received the B.S. degree from Nagoya Institute of Technology, Nagoya, Japan, in 1974 and the M.S. and Ph.D. degrees from Tokyo Institute of Technology, Tokyo, Japan, in 1976 and 1979, respectively, all in electrical engineering.

In 1979, he joined Nagaoka University of Technology, Nagaoka, Japan, as an Assistant and then Associate Professor in the Department of Electrical Engineering. Since 1991, he has been a Full Professor. In 1987, he was a Visiting Scientist at Massachusetts Institute of Technology, Cambridge, for ten months. From March to August 1996, he was a Visiting Professor, first at the University of Wisconsin, Madison, and then at Massachusetts Institute of Technology. His research interests include ac motor drives, high-frequency resonant inverters for induction heating and corona discharge treatment, and utility applications of power electronics, such as active filters, static var compensators, and FACTS devices.

Prof. Akagi has received eight Society and Committee Prize Paper Awards from the IEEE Industry Applications Society, including the First Prize Paper Award from the IEEE TRANSACTIONS ON INDUSTRY APPLICATIONS for 1991 $\mathrm{He}$ is a Distinguished Lecturer of the IEEE Industry Applications and IEEE Power Electronics Societies for 1998-1999. 